\title{
KKN PPM PEMBELAJARAN FISIKA BERBASIS ALAM DI SMK KRISTEN IMANUEL LAIKIT
}

\author{
Djeli Tulandi \\ Universitas Negeri Manado \\ djelitulandi@unima.ac.id
}

\begin{abstract}
Abstrak
Pemberdayaan masyarakat khususnya komunitas mahasiswa, guru dan siswa dalam menghadapi tantangan di era 4.0 dan era new normal merupakan hal penting untuk dilakukan dan perlu mendapat perhatian dari negara dan masyarakat. KKN PPM pembelajaran berbasis alam yang terintegrasi dalam kegiatan blended learning yang dilaksnakan di SMK Imanuel Laikit Minahasa Utara dan juga melibatkan mahasiwa bertujuan agar dapat meningkatkan kompetensi siswa dalam penguasaan konsep fisika dan meningkatkan kemampuan mahasiswa mendesain bahan ajar blended learning. Metode kegiatan adalah implementasi blended learning melalui kegiatan tatapmuka dan melakukan pengamatan di alam khususnya di PLTA Tonsealama Minahasa. Hasil kegiatan KKN PPM menunjukkan bahwa atmosfer akademik di sekolah semakin baik, mahasiswa mampu mengimplementasikan kegiatan blended learning dan bahan ajar yang dikembangkan layak digunakan dalam pembelajaran fisika. Pemberdayaan masyarakat lewat program KKN-PPM merupakan suatu kegiatan inovasi yang diharapkan terus dilakukan oleh pihak perguruan tinggi.
\end{abstract}

Kata kunci: atmosfer akademik, blended learnig, pembelajaran berbasis alam

\section{PENDAHULUAN}

Menghadapi berbagai tantangan dalam dunia yang serba kompleks permasalahannya maka masyarakat harus siap menghadapinya. Program pemberdayaan yang dapat menstimulasi kemandirian masyarakat penting untuk dilakukan . Program yang sifatnya partisipatif, direncanakan, dilaksanakan, diawasi dan dievaluasi merupakan Langkah Langkah pemberdayaan yang harus diikuti, namun untuk sampai pada tingkat tersebut perlu waktu dan proses pendampingan yang melibatkan pendamping yang berkomitmen tinggi terhadap pemberdayaan masyarakat. Pemberdayaan di komunitas sekolah menjadi penting dalam mengantisipasi perkembangan di era 4.0 dan era pandemic covid-19.
SMK Kristen Imanuel Laikit tergolong masih baru karena beroperasi sejak tahun 2014 yang ada di Kabupaten Minahasa Utara. Terdiri dari dua program yakni Teknik otomotif dan Teknologi informasi. Jumlah siswa kurang lebih 30. SMK Kristen Imanuel merupakan SMK yang dikelolah Swasta dan yang sudah menerapkan kurikulum 2013. Guru fisika disekolah ini bukan lulusan S1 Pendidikan Fisika tapi jurusan teknik otomotif. Lulusan SMK Kristen Imanuel ini umumnya menjadi operator internet di berbagai bidang. Demikian halnya yang lulusan Teknik otomotif bekerja sebagai teknisi di dealer kendaraan dan kerja dibengkel, di pabrik dll. Hasil kajian tim KKN PPM terhadap program pembelajaran di SMK Kristen Imanuel laikit menunjukkan bahwa pembelajarannya berjalan sesuai program 


\section{Jurnal ABDIMAS, Vol. 13, No. 2, Agustus 2020 \\ ISSN: 1979-0953 | e-ISSN: 2598-6066}

hanya saja beberapa topik fisika seperti Listrik, thermodinamika, MGBSF di kabupaten minahasa belum terinci secara detail bagaimana strategi mencapai kompetensi anak didik sesuai harapan. Dalam permendikbud no.21 tahun 2016 menyebutkan: Kompetensi yang hendak dimiliki para siswa lulusan SMK adalah: Mengembangkan sikap rasa ingin tahu, jujur, tanggung jawab, logis, kritis, analitis, dan kreatif melalui pembelajaran fisika. Merumuskan permasalahan yang berkaitan dengan fenomena fisika benda, merumuskan hipotesis, mendesain dan melaksanakan eksperimen, melakukan pengukuran secara teliti, mencatat dan menyajikan hasil dalam bentuk tabel dan grafik, menyimpulkan, serta melaporkan hasilnya secara lisan maupun tertulis. - Menganalisis konsep, prinsip, dan hukum mekanika, fluida, termodinamika, gelombang, dan optik serta menerapkan metakognisi dalam menjelaskan fenomena alam dan penyelesaian masalah kehidupan. Memodifikasi atau merancang proyek sederhana berkaitan dengan penerapan konsep mekanika, fluida, termodinamika, gelombang, atau optik.

Dalam rangka meluluskan siswa dengan kompetensi seperti disebutkan di atas, maka perlunya kesiapan sekolah dalam hal sarana prasarana dan juga kesiapan guru [1 ]. Peran mahasisiwa semester IV yang dilibatkan dalam program KKN PPM ini adalah menjadi tutor/pendamping bagi siswa maupun bagi mahasiswa KKN_PPM. Disamping memperhatikan tujuan pembelajaran dan kompetensi lulusan yang harus dicapai, pengembangan strategi pembelajaran juga harus mengacu pada hasil-hasil penelitian. KKN PPM pembelajaran fisika berbasis fenomena/peristiwa alam akan membantu para guru mendesain pembelajaran melalui tugas-tugas tambahan di luar sekolah dimana lewat penyelesaian tugas-tugas tambahan ini dapat menguatkan kompetensi siswa. Pendampingan yang dilakukan tim melalui kegiatan KKN PPM melalui pendalaman materi dapat meminimalisir miskonsepsi para guru terhadap suatu konsep fisika karena kenyataannnya masih ada guru fisika yang belum memahami secarah utuh konsep dan penerapan fisika. Hasil penelitian[2] menyebutkan bahwa beberapa guru fisika masih mengalami miskonsepsi tentang konsep optic. Melalui pengamatan peristiwa alam akan dilakukan pengembangan format pengamatan/lembar kerja. [3] menjelaskan bahwa kemampuan mengindentifikasi dan mengkategorikan masalah berdasarkan prinsip dan konteks fisika yang mendasarinya merupakan ukuran pemahaman fisika dari seorang guru. Selanjutnya hasil penelitian [4] menjelaskan bahwa pentingnya guru fisika mengembangkan lembar kerja siswa terpandu dalam strategi belajar fisika. Melalui kegiatan KKN PPM akan mendesain pembelajaran yang mengintegrasikan hasilhasil penelitian dan kompetensi siswa dalam pembelajaran berbasis fenomena/peristiwa alam. Tujuan utama fisika adalah memahami bagaimana alam semesta berperilaku. Fisika 
berasal dari kata yang berarti "Pengetahuan tentang Alam". Bukan hanya karena ini tetapi tujuan utama Fisika adalah Memahami bagaimana hukum-hukum fisika menentukan perilaku alam semesta [5].

Hasil survey menunjukkan bahwa belum ada siswa dari SMK di kabupaten Minahasa yang mendapat nilai tertinggi ujian Nasional. Jumlah siswa SMK dari kabupaten Minahasa yang ikut olympiade fisika masih sangat kurang. Para guru fisika selama ini dalam pembelajarannya lebih banyak mengambil referensi pada buku-buku yang tersedia serta laboratorium disekolah, dan pada umumnya belum menjadikan fenomena alam sekitar sebagai referensi pembelajaran fisika. Kemampuan guru dalam menyusun bahan ajar juga masih rendah [6]. Hal ini mengindikasikan bahwa kinerja para guru fisika di Kabupaten Minahasa perlu ditingkatkan.

Kabupaten minahasa memiliki lingkungan alam yang memudahkan para guru menerapkan pembelajaran berbasis fenomena/peristiwa alam dengan metode saintifik. Lingkugan alam yang dimaksud antara lain Air terjun Tonsea lama, air terjun di Desa pinaras dan Danau Tondano. Umumnya guru dan siswa cukup familiar dan sangat mengenal lokasi ini sehingga memungkinkan guru menjadikan lokasi ini sebagai laboratorium alam. Hal ini dapat membantu guru mengkondisikan /mendorong siswa melakukan aktivitas pembelajaran berbasis fenomena alam. Melalui peristiwa alam air terjun siswa dapat melakukan pengamatan fenomena fisis terkait konsep fisika mekanika, energi, teori medan, fluida, bunyi dll) [7]. Kemudian Danau Tondano, Danau Linow, air terjun, tanah longsor, laut dapat dijadikan lokasi pengamatan terkait dengan konsep fisika energi, gelombang, fluida, gelombang elektromagnetik, dlsb)[7,8].

Kehadiran lingkungan alam seperti Air terjun Danau Tondano dan alam sekitar lainnya memungkinkan sekolah dapat menerapkan prinsip-prinsip pembelajaran sebagaimana yang tercantum dalam permen 65 tahun 2013 antara lain menyebutkan:Mendorong peserta didik untuk selalu mencari tahu, Guru bukan satu-satunya sumber belajar tapi harus berbasis aneka sumber belajar, Pendekatan tekstual menuju proses sebagai penguatan penggunaan pendekatan ilmiah, Pembelajaran berbasis konten menuju pembelajaran berbasis kompetensi, Pembelajaran parsial menuju pembelajaran terpadu;

Pembelajaran berbasis fenomena alam akan melengkapi keseluruhan proses pembelajaran di sekolah sehingga dengan demikian proses pembelajaran secara utuh melahirkan kualitas pribadi yang mencerminkan keutuhan penguasaan sikap, pengetahuan, dan keterampilan.

Hal-hal yang dikemukaan di atas mendasari tujuan pelaksanaan kegiatan yakni:

1. Meningkatkan kompetensi guru danmahasisiwa KKN calon guru mendesain pembelajaran dengan pendekatan saintifik berbasis 
pengamatan di alam

2. Meningkatkan kompetensi
belajar siswa

\section{Permasalahan Mitra}

Perkembangan IPTEK yang begitu cepat, mengharuskan masyarakat kita harus melek sains. Melek sains sangat penting dalam lapangan pekerjaan. Banyak sekali pekerjaan yang membutuhkan ketrampilan tingkat tinggi, membutuhkan tenaga kerja yang dapat belajar, berpikir kreatif, memecahkan masalah dan membuat keputusan. Klausner (1996) menyatakan bahwa pemahaman sains dan proses-proses sains memberikan kontribusi yang penting kepada kemampuan kemampuan tersebut.

Hasil observasi empirik yang dilakukan Dikmenjur (2004) mengindikasikan, bahwa sebagian besar lulusan Sekolah Menengah Kejuruan (SMK) kurang mampu menyesuaikan diri dengan perubahan IPTEK, dan kurang bisa mengembangkan diri. Tingkat keterkaitan dan kesesuaian antara lulusan yang ada dengan kebutuhan tenaga kerja dalam masyarakat masih rendah. Hasil Pendidikan saat ini belum menunjukkan relevansi yang signifikan dengan kebutuhan masyarakat. Lahirnya program merdeka belajar dari
Kemendikbud merupakan jawaban terhadap permasalahan di atas. Karena itu Kegiatan KKN PPM yang melibatkan mahasisiwa ini penting. Dalam masa yang sangat dinamis ini, perguruan tinggi harus meresponse secara cepat dan tepat. Diperlukan transformasi pembelajaran untuk bisa membekali dan menyiapkan lulusan Pendidikan tinggi agar menjadi generasi yang uggul. Generasi yang tanggap dan siap menghadapi tantangan zamannya, tanpa tercerabut dari akar budaya bangsanya.

Saat ini kreativitas dan inovasi menjadi kata kunci penting untuk memastikan pembangunan Indonesia yang berkelanjutan. Para mahasiswa yang saat ini belajar di Perguruan Tinggi, harus disiapkan menjadi pembelajar sejati yang terampil, lentur dan ulet (agile learner). Kebijakan Merdeka Belajar - Kampus Merdeka yang diluncurkan oleh Menteri Pendidikan dan Kebudayaan merupakan kerangka untuk menyiapkan mahasiswa menjadi sarjana yang tangguh, relevan dengan kebutuhan zaman, dan siap menjadi pemimpin dengan semangat kebangsaan yang tinggi .

Masih sangat sedikit program pemberdayaan yang dilakukan untuk masyarakat komunitas sekolah sehingga banyak yang belum tersentuh oleh upaya perbaikan kualitas pembelajaran. Belum 
terjalinnya kemitraan yang kondusif antara perguruan tinggi dengan masyarakat sehingga belum dapat berlangsungnya penerapan hasil penelitian dan riset yang sesuai untuk pemberdayaan masyarakat.

Karena itu permasalahan mitra dapat dirumuskan sebagai berikut:

- Bagaimanakah meningkatkan kemampuan para guru fisika di SMK Kristen Laikit dalam mengimplementasikan blended learning.

- Bagaimana meningkatkan kompetensimahasiswa dalam mendesain kegiatan pembelajaran berbasis lingkunag alam

- Bagaimana mensinergikan strategi pembelajaran yang terintegrasi antara pembelajaran daring dan pengamatan langsung fenomena alam

- Bagaimanakah meningkatkan kompetensi siswa sehingga memiliki daya saing dilapagan pekerjaan.

\section{TINJAUAN PUSTAKA}

\section{Belajar dan Hasil Belajar}

Pengertian secara psikologis (Amalia, 2013), belajar merupakan suatu proses perubahan yaitu perubahan tingkah laku sebagai hasil dari interaksi dengan lingkungannya dalam memenuhi kebutuhan hidupnya. Perubahanperubahan tersebut akan nyata dalam seluruh aspek tingkah laku.
Menurut Kurniawan yang dikutip oleh Kilay (2016), mengatakan "belajar itu sebagai proses aktif internal individu dimana melalui pengalamannya berinteraksi dengan lingkungan menyebabkan terjadinya perubahan tingkah laku yang relatif permanen".

Menurut Ernest R. Hilgard yang dikutip oleh Munawar (2011), belajar merupakan proses perbuatan yang dilakukan dengan sengaja, yang kemudian menimbulkan perubahan, yang keadaanya berbeda dari perubahan yang ditimbulkan oleh lainnya

Dari beberapa pengertian di atas, dapat disimpulkan bahwa belajar adalah suatu proses proses aktif internal yang dilakukan dengan sengaja untuk menghasilkan perubahan-perubahan pengetahuan dan tingkah laku sebagai hasil interaksi dengan lingkungannya.

Hasil belajar merupakan tujuan akhir dilaksanakannya kegiatan pembelajaran di sekolah. Hasil belajar dapat ditingkatkan melalui usaha sadar yang dilakukan secara sistematis mengarah kepada perubahan yang positif yang kemudian disebut dengan proses belajar. Akhir dari proses belajar adalah perolehan suatu hasil belajar peserta didik. Hasil belajar digunakan untuk mengetahui sebatas mana peserta didik dapat memahami serta mengerti materi tersebut

Definisi Blended Learning

Secara etimologi istilah blended learning terdiri dari dua kata blended dan learning. Kata blend berarti campuran atau perpaduan. Sedangkan learning memiliki makna umum 


\section{Jurnal ABDIMAS, Vol. 13, No. 2, Agustus 2020 \\ ISSN: 1979-0953 | e-ISSN: 2598-6066}

yakni belajar (Zaka, 2013). Dengan demikian blended learning mengandung makna yaitu pola pembelajaran yang mengandung unsur percampuran atau penggabungan antara satu pola dengan pola lainnya. Blended learning adalah konsep belajar hibrida yang mengintegrasikan sesi kelas tradisional dan elemen e-learning dalam upaya untuk menggabungkan manfaat dari kedua bentuk pembelajaran.

Driscoll dan Carliner [9] menyatakan bahwa blended learning mengintegrasikan atau menggabungkan program belajar dalam format yang berbeda dalam mencapai tujuan umum.

Sedangkan Thorne menggambarkan blended learning sebagai kesempatan untuk mengintegrasikan kemajuan inovatif dan teknologi yang ditawarkan oleh pembelajaran online dengan interaksi dan partisipasi dari pembelajaran tradisional.

Berdasarkan beberapa pendapat di atas, penulis menyimpulkan bahwa blended learning adalah metode pembelajaran yang mengkombinasi strategi penyampaikan pembelajaran menggunakan kegiatan tatap muka (face to face), pembelajaran berbasis komputer (offline), dan komputer secara online (internet dan mobile learning).

Pembelajaran berbasis Blended learning berkembang sekitar tahun 2000 dan sekarang banyak digunakan di Amerika Utara, Inggris, Australia, kalangan perguruan tinggi dan dunia pelatihan. Pembelajaran blended dapat menggabungkan pembelajaran tatap muka (face-to-face) dengan pembelajaran berbasis komputer. Artinya, pembelajaran dengan pendekatan teknologi pembelajaran dengan kombinasi sumber-sumber belajar tatap muka dengan pengajar maupun yang dimuat dalam media komputer, telepon seluler atau iPhone, saluran televisi satelit, konferensi video, dan media elektronik lainnya. Tujuan utama pembelajaran blended adalah memberikan kesempatan bagi berbagai karakteristik peserta didik agar terjadi belajar mandiri, berkelanjutan, dan berkembang sepanjang hayat, sehingga belajar akan menjadi lebih efektif, lebih efisien, dan lebih menarik.

\section{Induksi elekromagnetik}

Induksi elektromagnetik adalah proses ketika konduktor yang diletakkan di suatu medan magnet yang bergerak/berubah (atau konduktornya yang digerakkan melewati medan magnet yang diam) menyebabkan terproduksinya voltase disepanjang konduktor. Proses induksi elektromagnetik ini menghasilkan arus listrik.

Michael Faraday merupakan ilmuwan yang menemukan fenomena ini pada tahun 1831 dan James Clerk Maxwell merupakan ilmuwan yang mendeskripsikannya secara matematik sebagai Hukum Induksi Faraday. Nama formal persamaan yang mendefinisikan karakteristik induksi medan elektromagnetik dari fluks magnetik (perubahan pada medan magnet) disebut sebagai Hukum Faraday, yang kemudian digeneralisasikan menjadi persamaan Maxwell-Faraday, satu dari empat persamaan pada teori elektromagnetik oleh 
James Clerk Maxwell; persamaan ini mendefinisikan hubungan antara perubahan medan listrik dan medan magnet. Selain itu, terdapat Hukum Lorentz yang mendeskripsikan arah dari medan induksi.

Proses induksi elektromagnetik dapat bekerja pula secara kebalikannya, jadi pergerakan arus listrik dapat menghasilkan sebuah medan magnetik. Faktanya, sebuah magnet biasa memiliki medan magnet akibat gerakan individual elektron-elektron dalam atom-atom penyusun magnet; elektronelektron tersebut bergerak secara seragam sehingga menghasilkan medan magnet uniform.

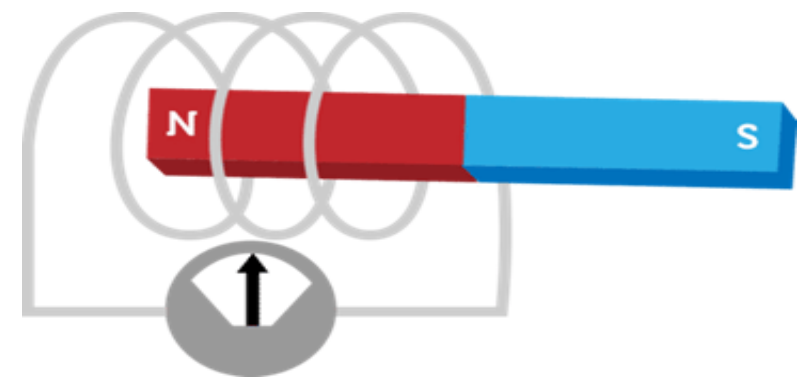

Gambar. 1. Induksi Elektromagnetik https://www.studiobelajar.com/induksielektromagnetik/

Induksi elektromagnetik telah diterapkan pada berbagai teknologi seperti komponen-komponen elektrikal: induktor dan transformator, dan alat-alat yang sangat krusial: motor elektrik dan generator.

\section{METODE}

\section{Waktu Pelaksanaan}

Kegiatan KKN PPM ini dilaksakan sesuai dengan kegiatan KKN yang tertuang dalam
Kalender Akademik 2019/2020

Universitas Negeri Manado

Sasaran

Sasaran kegiatan KKN PPM ini adalah masyarakat komunitas SMK Kristen Imanuel Laikit, mahasiswa KKN dan Mahasiswa semester IV Prodi Pendidikan Fisika UNIMA

Metode pendekatan yang digunakan adalah pemberdayaan dengan menggunakan tahapan/ langkah kegiatan PKM. Tahapan tersebut adalah sebagai berikut:

\section{Tahap Persiapan}

Pada tahap persiapan dilakukan koordinasi dengan pemerintah Kabupaten Minahasa Utara khususnya Bupati Minahsa Utara untuck kegiatan KKN di wilayahnya dan Dinas pendidikan untuk mendapatkan ijin kerjasama dengan sekolah. Selanjutnya berkoordinasi dengan pengurus pemimpin sekolah tentang rencana pelaksanaan kegiatan PKM sekaligus mengiventarisir keberadaan siswa di SMK Kristen Imanuel Laikit dan menentukan tempat pelaksanaan dan jadwal kegiatan.

Tim kerja PKM juga menyiapkan materi dan perangkat pelatihan yang dibutuhkan juga peralatan seperti LCD proyector, handycam dll.

\section{Tahap Pelaksanaan}

Tahap pelaksanaan kegiatan dapat digambarkan sebagai berikut: 
Jurnal ABDIMAS, Vol. 13, No. 2, Agustus 2020

ISSN: 1979-0953 | e-ISSN: 2598-6066

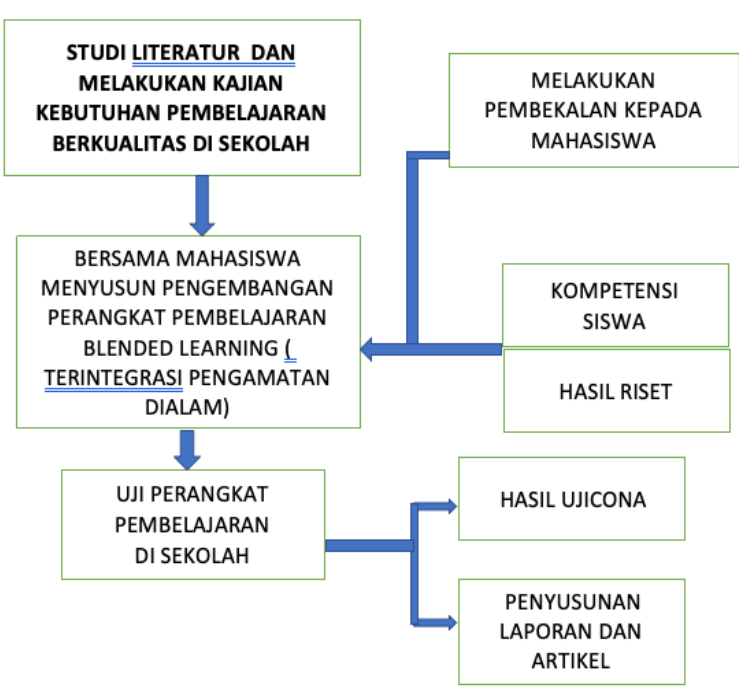

HASIL DAN PEMBAHASAN

Hasil yang telah dicapai dalam kegiatan KKN PPM UNIMA 2020 ini adalah sebagai berikut;

a. Mahasiswa peserta KKN PPM telah memiliki kemampuan paket pembelajaran blended learning

b. Mahasiswa perserta KKN PPM telah memiliki keterampilan menjadi mentor dalam mendampingi

Masyarakat/sekolah untuk implementasi pembelajaran secara daring dan pengamatan dilapangan(blended learning).

c. Para guru mendapat pengalaman melakukan pembelajaran yang mengintegrasikan pembelajaran daring dan pengamatan dilapangan.

d. Tercipta kondusifitas belajar siswa yang mandiri, kreatif mampu memecahkan masalah.
Pelaksanaan KKN PPM di bulan Februari sampai bulan Maret 2020. Jumlah mahasiswa KKN 6 orang dan mahasiswa semester IV Prodi Pendidikan Fisika 20 mahasiswa. Jumlah siswa SMK Kristen Imanuel Laikit 22 siswa. Guru yang terlibat kegiatan 2 orang.

Hasil implementasi pembelajaran yang mengintegrasikan pembelajaran daring dengan pengamatan langsung dilapangan dapat dijelaskan sebagi berikut:

Hasil Uji Pakar

Setelah pengembangan produk bahan ajar Fisika dan rekayasa perangkat lunak menggunakan program multimedia berbasis blended learning selesai, maka hasil pengembangan produk diuji oleh pakar berupa ahli materi pembelajaran dan ahli media. Berikut hasil uji Pakar/Ahli Materi dari pembelajaran yang dikembangkan :

Uji Pakar/Ahli Materi yang dilakukan pada tahap pertama kepada 2 orang Ahli Materi, dengan hasil pengujian sebagai berikut : Berdasarkan hasil uji pakar untuk materi dan media pembelajaran meggunakan uji skala likert, produk bahan ajar mendapat skor persentase 92,5\% untuk Uji Pakar/Ahli Materi dan Persentase 93,1\% untuk Uji Pakar/Ahli Media sesuai dengan range persentase dan kriteria lualitatif, maka hasil tersebut berada pada kriteria Sangat Baik. Maka hasil pengembangan produk bahan ajar dinyatakan layak untuk diimplementasikan oleh peneliti dalam bentuk uji kelompok kecil. 
Tabel 4.1 Hasil Uji Kelompok Kecil Aspek

Pembelajaran

\begin{tabular}{|c|c|c|c|c|c|}
\hline \multirow{2}{*}{ No } & \multirow{2}{*}{ Aspek Pembelajaran } & \multicolumn{4}{|c|}{ Penilaian } \\
\hline & & 1 & 2 & 3 & 4 \\
\hline \multicolumn{6}{|c|}{ Interaltivitas } \\
\hline 1 & Peserta didik lebih responsive & 0 & 1 & 2 & 3 \\
\hline 2 & $\begin{array}{l}\text { Interaktifitas membantu menyampaikan materi } \\
\text { pembelajaran dengan baik }\end{array}$ & 0 & 1 & 3 & 2 \\
\hline \multicolumn{6}{|c|}{ Minat } \\
\hline 3 & $\begin{array}{l}\text { Menarik perhatian peserta didik untuk belajar karena } \\
\text { dilengkapi aspek visual dan audio }\end{array}$ & 0 & 0 & 0 & 6 \\
\hline \multicolumn{6}{|c|}{ Kesesuaian bidang studi } \\
\hline 4 & $\begin{array}{l}\text { Materi listrik dinamis dapat disampaikan dengan baik } \\
\text { menggunakan perangkat lunak }\end{array}$ & 0 & 0 & 1 & 5 \\
\hline
\end{tabular}

Blended Learning adalah model pembelajaran yang mengkombinasi stragtegi penyampaian pembelajaran menggunakan kegiatan tatap muka (face to face), pembelajaran berbasis komputer, dan komputer secara online (internet dan mobile learning). Secara mendasar terdapat tiga tahapan dasar dalam model blended learning yang mengacu pembelajaran berbasis e-learning, seperti yang diusulkan oleh Grant Ramsay [10], yakni: (1) seeking of information, (2) acquisition of information, dan (3) synthesizing of knowledge. Tahapan seeking of information, mencakup pencarian informasi dari berbagai sumber informasi yang tersedia pada e-learning, memilih secara kritis diantara sumber penyedia informasi dengan berpatokan pada content of relevantion, content of validity/releability, dan academic clarity. Pengajar berperan sebagai pakar yang dapat memberikan masukan dan nasehat guna membatasi pebelajar dari tumpukan informasi potensial pada e-learning. Pada tahapan acquisition of information, pebelajar secara individual maupun dalam kelompok kooperatif-kolaboratif berupaya untuk menemukan, memahami, serta mengkonfrontasikannya dengan ide atau gagasan yang telah ada dalam pikiran pebelajar, kemudian menginterprestasikan informasi/pengetahuan dari berbagai sumber yang tersedia, sampai mereka mampu kembali mengkomunikasikan dan menginterpretasikan ide-ide dan hasil interprestasinya menggunakan fasilitas elearning. Tahap terakhir pembelajaran berbasis e-learning adalah tahap synthesizing of knowledge adalah mengkonstruksi/merekonstruksi pengetahuan melalui proses asimilasi dan akomodasi bertolak dari hasil analisis, diskusi dan perumusan kesimpulan dari informasi yang diperoleh. Tujuan utama pembelajaran blended learning adalah memberikan kesempatan bagi berbagai karakteristik peserta didik agar terjadi belajar mandiri, berkelanjutan dan berkembang sepanjang hayat, sehingga belajar akan menjadi lebih efektif, lebih efisien dan lebih menarik.

Pada kegiatan tatap muka dengan membawa siswa mengamati air terjun Tonsea lama, proses memutar turbin sampai menghasilkan energi listrik, siswa mengikuti dengan saksama dan serius sambil mengisi lembar pengamatan. Hasil kunjungan lapangan enunjukkan sisiwa dapat mengkaitkan materi pengamatan dan materi belajar lewat daring. 


\section{KESIMPULAN}

1. Berdasarkan hasil penelitian dan pembahasan yang telah dilakukan dapat disimpulkan bahwa telah dihasilkan paket pembelajaran fisika SMK topik induksi elektromagnetik berbasis blended learning yang menarik, efektif, dan layak digunakan .

2. Para mahasiswa baik mahasiswa KKN maupun mahasiwa semester IV prodi Pendidikan Fisika mendapatkan pengalaman menjadi mentor/pendamping siswa dalam implementasi blended learning

\section{REFERENSI}

[1].Ashad M,Ali M,Pasaribu M.Pengaruh Model Pembelajaran Berbasis Masalah Terhadap Hasil Belajar Fisika Pada Siswa Kelas XI SMA Negeri 5 Palu . Jurnal Pendidikan Fisika Tadulako.Vol 1 No 2:3943

[2].Gurell D.K, Eryilmaz A and Mcdermott L.C.2016. Identifying pre-service physics teachers' misconceptions and conceptual difficulties about geometrical optics. European Journal of Physics 37 (2016) 045705 (30pp)

[3].Masson A, Singh C.2016. Using categorization of problems as an instructional tool to help introductory students learn physics. Phys. Educ. 51 025009

[4].Sujarittham T, Emarat N, Arayathanitkul K, Sharma M D, Johnston I, and Tanamatayara J.2015. Developing specialized guided worksheets for active learning in physics lectures. Eur. J. Phys. 37 (2016) 025701 (17pp)

[5].Narang G, 2018. Bachelor of Science Physics, Lovely Professional University-
LPU https://www. quora.com/Why-isphysics-related-to-nature

[6.Sandy M, Setiawan A, Rusnayati H. 2012. Analisis Buku Ajar Fisika SMA Kelas $X$ di Kota Bandung Berdasarkan Komponen Literasi Sains. Universitas Pendidikan Indonesia

[7].Tulandi D. 2014. Buku Ajar Fisika Lingkungan

[8].Silangen, P. 2015. Model pengembangan danau Linow sebagai lab alam prodi fisika, konsentrasi geothermal FMIPA Unima. Universitas Negeri Manado [9]Wijayanti, W. 2017. Pengembangan perangkat blended learning berbasis LMS dengan model inkuiri pada materi listrik dinamis. [Skripsi]. Bandar Lampung : Universitas Lampung.

[10] Grant, R. 2001. Teaching and Learning With Information and Communication Technology: Succes Through a Whole School Approach. National Educational Computing Conference, July 25-27. Chicago. Copyright Office. (ERIC Document Reproduction Service No. ED462943) 